Acta Theriologica $36(3-4): 357$ - 362, 1991.

PL ISSN $0001-7051$

\title{
Regional and individual variation in body growth in winter of bank voles Clethrionomys glareolus
}

\author{
Lennart HANSSON
}

\begin{abstract}
Hansson L. 1991. Regional and individual variation in body growth in winter of bank voles Clethrionomys glareolus. Acta theriol. $36: 357-362$.

Small rodent body growth usually stagnates or is negative during winter but large individuals in dense populations exhibit pronounced winter growth. Growth of first generation laboratory bank voles Clethrionomys glareolus (Schreber, 1780) from cyclic and noncyclic populations, born in late summer - early autumn and bred under constant conditions, was examined up to 4 months of age. Weight increase between 2 and 4 months, corresponding to early winter growth, occurred only in one-fifth of the animals in most groups but in considerably more than half of the males from a cyclic population. Juvenile weights differed between populations in the same way as adult weights. Weights at 2 and 4 months as well as maximum weights were positively related to weaning weights. Winter growth correlated insignificantly or negatively with weaning weight in noncyclic animals and positively with weaning weights in cyclic animals. Individual differences were evidently genetically based as both parents and young were kept under identical conditions. Population differences appear to be adaptations to nutritional rather than social conditions.
\end{abstract}

Department of Wildlife Ecology, Swedish University of Agricultural Sciences, S-750 07 Uppsala, Sweden

Key words: body growth, winter, regional differences, Clethrionomys glareolus, Sweden

\section{Introduction}

Small rodents usually reproduce between May and September in northern areas (e.g. Kaikusalo 1972). Young born in late summer - early autumn do not mature sexually during the year of birth and grow to a fairly low weight in late autumn (Schwarz et al. 1964, Hansson 1984a). The weight usually remains at this low level or decreases in winter (Tanton 1969, Bobek 1971, Hansson 1990). However, rodent populations with high densities are characterized by especially heavy individuals (the Chitty effect: Krebs 1978, Lidicker and Ostfeld 1991). These large animals show continuous growth during the previous winter (Boonstra and Krebs 1979, Beacham 1980).

The large individuals in peak rodent populations have been thought to be especially aggressive and to limit further population growth (Chitty 1967, see Boonstra and Krebs 1979 for alternative interpretations). This has been the basis for one main idea of the regulation of rodent (and other animal) populations, viz. the Chitty hypothesis. It is thus important to understand the background to continuous winter growth in small rodents both in organismic and population ecology. 
Large animals are especially typical of cyclic populations (Krebs 1978; Hansson 1984a, 1985 ) and therefore an initial examination of variations in growth should address differences between cyclic and noncyclic populations. If there is a selection for large animals during population increases, according to Chitty $(1960,1967)$, then winter growth rates should differ between animals from increase and peak populations. Another explanation of varying growth rates may be sought in the nutritional state of the mothers and maternal effects on weanlings (Hansson 1984a, Boag and Boonstra 1987).

Young of one common rodent species, the bank vole Clethrionomys glareolus (Schreber, 1780) were born in the laboratory in late summer - early autumn by wild animals that were caught during the previous autumn as juveniles in three Swedish localities with different population dynamics. Their weight changes were examined during autumn - winter and related to their origin, including population phase, and weights as weanlings. Almost life-long periods of constant food and environmental conditions should preclude any differences in maternal conditions and any remaining variation in weanling weights should be genetically determined.

\section{Methods}

Juvenile voles were collected in early autumn $1979-1983$ at Revinge $\left(56^{\circ} \mathrm{N}\right)$, Uppsala $\left(60^{\circ} \mathrm{N}\right)$ and Strömsund $\left(64^{\circ} \mathrm{N}\right)$. They were kept at Uppsala for at least one year as monogamous pairs in laboratory mouse cages on laboratory mouse pellets and in natural light. Offspring that were used for the growth studies were born mainly at the turn of August - September but c. $20 \%$ in late July.

Revinge rodent populations show noncyclic dynamics, Strömsund populations pronounced cyclic dynamics, and Uppsala rodents are intermediate but mostly noncyclic (Hansson and Henttonen 1985). The northern populations had a peak in $1980-81$ (Hansson 1984b).

The young were weaned and weighed at 20 days (Gustafsson et al. 1980). They were marked individually and kept in litters until 4 months of age. They were weighed at 2 and 4 months, corresponding to early (c. 1 November) and mid winter (c. 1 January). C. glareolus usually have a weight decline in late November December and minimum winter weights are found in January or February (Kaikusalo 1972, Hansson 1990). Animals increasing in weight between 2 and 4 months of age were therefore assumed to grow during the winter. A quantitative measure of winter growth rate was defined for each individual as the ratio between weights at 4 and 2 months.

Many of the young animals were retained for one year in monogameous pairs. They were weighed at the end of each month. Maximum weights were easily assessed in males while the weight varied greatly in females due to pregnancies and lactation. Instead, a maximum prebreeding weight was defined for females as the weight in late April or, if the animals were breeding before mid-May, one month before the first litter. Pregnancy lasts for c. 20 days in this species (Gustafsson et al. 1980).

\section{Results}

The proportion of animals that increased in weight between 2 and 4 months of age did not differ between late summer (July - August) and early autumn (September) births. It did not differ between the Revinge and Uppsala localities (Table 1). However, Strömsund males showed a significantly higher proportion of young with weight increase during winter ( $G=26.26, p<0.001$ in relation to Revinge and Uppsala males). Strömsund females also demonstrated a slight tendency for more common winter growth. The Strömsund parents were 
Table 1. Proportions of juveniles born in late summer - autumn with weight increases between the second and fourth months of life.

\begin{tabular}{llccc}
\hline Locality & Sex & N & Increase & $\%$ \\
\hline \multirow{2}{*}{ Revinge } & Male & 95 & 19 & 20 \\
& Female & 73 & 15 & 21 \\
\multirow{3}{*}{ Uppsala } & Male & 16 & 3 & 19 \\
& Female & 19 & 3 & 16 \\
Strömsund & Male & 32 & 22 & 69 \\
& Female & 24 & 7 & 29 \\
\hline
\end{tabular}

Table 2. Regional differences in weights (g) at weaning and 4 months of age.

\begin{tabular}{llccccc}
\hline \multirow{2}{*}{ Region } & \multirow{2}{*}{ Sex } & $\mathrm{N}$ & $\overline{\mathrm{x}}$ & $\mathrm{SE}$ & $\overline{\mathrm{x}}$ & $\mathrm{SE}$ \\
\hline Revinge & Males & 95 & 10.1 & 0.2 & 14.9 & 0.2 \\
Uppsala & Males & 16 & 11.4 & 0.3 & 19.5 & 0.7 \\
Strömsund & Males & 32 & 11.9 & 0.3 & 21.1 & 0.7 \\
$F$ & & \multicolumn{2}{c}{17.17} & \multicolumn{2}{c}{63.41} \\
$p$ & & \multicolumn{2}{c}{$<.001$} & \multicolumn{2}{c}{$<.001$} \\
Revinge & Females & 73 & 9.9 & 0.2 & 13.5 & 0.2 \\
Uppsala & Females & 19 & 10.6 & 0.4 & 16.2 & 0.5 \\
Strömsund & Females & 24 & 10.8 & 0.5 & 16.8 & 0.8 \\
$F$ & & \multicolumn{2}{c}{3.25} & \multicolumn{2}{c}{21.51} \\
$p$ & & \multicolumn{4}{c}{$<.05$} & \multicolumn{2}{c}{$<.001$} \\
\hline
\end{tabular}

Table 3. Correlations ( $r$ and $p$ ) between weaning weights and successive weights and weight changes (weight ratio) between the second and fourth months.

\begin{tabular}{|c|c|c|c|c|c|}
\hline \multirow{2}{*}{ Region } & \multirow{2}{*}{ Sex } & \multirow{2}{*}{$\mathrm{N}$} & \multicolumn{2}{|c|}{ Weight } & \multirow{2}{*}{$\begin{array}{l}\text { Weight } \\
\text { ratio }\end{array}$} \\
\hline & & & 2 months & 4 months & \\
\hline \multirow[t]{2}{*}{ Revinge } & Males & 95 & $\begin{array}{c}0.47 \\
<.001\end{array}$ & $\begin{array}{l}0.26 \\
<.05\end{array}$ & $\begin{array}{c}-0.28 \\
<.01\end{array}$ \\
\hline & Females & 73 & $\begin{array}{c}0.48 \\
<.001\end{array}$ & $\begin{array}{c}0.54 \\
<.001\end{array}$ & $\begin{array}{l}0.03 \\
\text { NS }\end{array}$ \\
\hline \multirow[t]{2}{*}{ Uppsala } & Males & 12 & $\begin{array}{l}0.33 \\
\text { NS }\end{array}$ & $\begin{array}{l}0.61 \\
<.05\end{array}$ & $\begin{array}{c}0.37 \\
\text { NS }\end{array}$ \\
\hline & Females & 19 & $\begin{array}{c}0.81 \\
<.001\end{array}$ & $\begin{array}{l}0.67 \\
<.01\end{array}$ & $\begin{array}{c}-0.41 \\
\text { NS }\end{array}$ \\
\hline \multirow[t]{2}{*}{ Strömsund } & Males & 32 & $\begin{array}{c}0.57 \\
<.001\end{array}$ & $\begin{array}{l}0.65 \\
<.001\end{array}$ & $\begin{array}{l}0.36 \\
<.05\end{array}$ \\
\hline & Females & 24 & $\begin{array}{l}0.28 \\
\text { NS }\end{array}$ & $\begin{array}{c}0.68 \\
<.001\end{array}$ & $\begin{array}{l}0.62 \\
<.01\end{array}$ \\
\hline
\end{tabular}


only caught during two years, the increase year 1981 and the peak - decline year 1982, due to the low numbers obtainable in crash years. However, the proportion of males that grew through the winter did not differ between animals emanating from these two years $(G=1.70$, NS).

Juvenile weights differed significantly between provenances both at weaning and at 4 months and both for males and females (Table 2). Revinge young were considerably lighter than those from Uppsala and Strömsund. Strömsund young were only negligibly larger than Uppsala young, except for 4-month males. The differences increased with age.

Juvenile weights at 2 months were usually, and at 4 months always, significantly related to weaning weights (Table 3). The winter weight changes (weight ratios) did not correlate with weaning weight, or correlated negatively, in Revinge and Uppsala animals. They were significantly positively related to weaning weights in Strömsund animals, both males and females.

Weaning weights correlated significantly with maximum weights in the total number of males $(r=0.55, \mathrm{~N}=40, p<0.001)$ and females $(r=0.54, \mathrm{~N}=51, p<0.001)$ kept for a vhole year. This correlation was significant in Revinge males $(r=0.39, \mathrm{~N}=27, p<0.05)$ and fenales $(r=0.57, \mathrm{~N}=35, p<0.001)$ but not in the less numerous Uppsala or Strömsund animals.

\section{Discussion}

The controlled breeding demonstrated a more common winter growth in animals from a cyclic population, in accordance with differences observed in the field between cyclic and noncyclic animals (Krebs 1978, Hansson 1984a). However, the mean body size was also larger in the cyclic than in the noncyclic population, both in adults (Hansson 1985) and in young (present results). Scandinavian cyclic populations occur in more northern areas than noncyclic populations (Hansson and Henttonen 1985) but this geographical gradient does not occır in North America (Hansson and Henttonen 1985, Taitt and Krebs 1985). Still, large-sized individuals occur in cyclic or dense populations throughout North America (Boonstra and Krebs 1979, Lidicker and Ostfeld 1991). Climatic adaptations thus seem unimportant and the weight differences are clearly related to type of population dynamics (e.g. Hansson and Jasrola 1989).

Large animals do not demonstrate any consistent advantage related to social behavioir in dense populations of various microtine species (Boonstra and Krebs 1979, Lidicker and Osfeld 1991). Similarly, the proportions of large individuals did not vary between population phases in this study. The weight and growth differences were at least equally pronounced in males as in females in this study. This is a further indication that they were not due to aggressive behaviour as $C$. glareolus males are not territorial while $C$. glareolus females are (Bujdska 1973, Bujalska and Grum 1989). Thus, other factors than pure density or social behaviour but covarying with dynamics, have to be considered to understand the growth differences.

Parents were kept under constant conditions, including one fixed food, for almost a year before production of the young that were analysed for growth rates. Therefore, environmental, including maternal, influences should be negligible and the weight variation genetically based. 
An earlier study also demonstrated that body size, at least in male C. glareolus from noncyclic populations, was clearly heritable (Hansson 1988).

Relative juvenile and adult weights were already laid down at weaning but weaning weights did not give good predictions of the change during the winter, except in the Strömsund animals. Thus, it seems to be generally favourable to grow during the winter and to be large in the cyclic population. This difference can be related to different nutritional strategies in the two types of populations: cyclic animals appear more folivorous, probably due to temporarily limited food quality, than noncyclic rodents (Hansson 1985, Hansson and Jaarola 1989) and folivorous rodents have to be larger to harbour a more extensive digestive tract (Hansson 1987). There was a certain variability in growth rates also in the noncyclic animals and thus selection could easily work under more dense conditions to increase the proportion of large animals.

In conclusion, the present analysis indicates that body size differences are not caused by proximate external influences but are genetically based. This polymorphy is possibly a consequence of temporary poor nutritional conditions. This idea can be examined further by studies of survival and reproduction under varying nutritional conditions by small- and large-sized individuals.

Acknowledgements: The work was supported by the Swedish Natural Science Research Council. Discussions on large-sized animals with $\mathrm{W}$. Z. Lidicker were profitable.

\section{References}

Beacham T. D. 1980. Growth rates of the vole Microtus townsendii during a population cycle. Oikos 35: $99-106$.

Bobek B. 1971. Influence of population density upon rodent production in a deciduous forest. Ann. Zool. Fennici 8: 137 - 144 .

Boonstra R. and Boag P. T. 1987. A test of the Chitty hypothesis: Inheritance of life-history traits in meadow voles Microtus pennsylvanicus. Evolution 41: 929 - 947.

Boonstra R. and Krebs C. J. 1979. Viability of large- and small-sized adults in fluctuating vole populations. Ecology 60: $567-573$.

Bujalska G. 1973. The role of spacing behaviour among females in the regulation of reproduction in the bank vole. J. Reprod. Fert., Suppl. 19: $461-472$.

Bujalska G. and Grum L. 1989. Social organization of the bank vole (Clethrionomys glareolus, Schreber 1780) and its demographic consequences: a model. Oecologia (Berl.) 80: $70-81$.

Chitty D. 1960. Population processes in the vole and their relevance to general theory. Can. J. Zool. 38: $99-113$.

Chitty D. 1967. The natural selection of self-regulatory behaviour in animal populations. Proc. Ecol. Soc. Aust. 2: $51-78$.

Gustafsson T., Andersson C. B. and Westlin L. M. 1980. Reproduction in a laboratory colony of bank vole, Clethrionomys glareolus. Can. J. Zool. 58: 1016-1021.

Hansson L. 1984a. Composition of cyclic and non-cyclic vole populations: On the causes of variation in individual quality among Clethrionomys glareolus in Sweden. Oecologia (Berl.) 63: 199 - 206.

Hansson L. 1984b. Predation as the factor causing extended low densities in microtine cycles. Oikos 43: $255-256$.

Hansson L. 1985. Geographic differences in bank voles Clethrionomys glareolus in relation to ecogeographical rules and possible demographic and nutritive strategies. Ann. Zool. Fennici 22: $319-328$.

Hansson L. 1987. An interpretation of rodent dynamics as due to trophic interactions. Oikos 50: $308-318$. 
Hansson L. 1988. Parent-offspring correltions for growth and reproduction in the vole Clethrionomys glareolus in relation to the Chitty hypothesis. Z. Säugetierk. 53: $7-10$.

Hansson L. 1990. Ultimate factors in the winter weight depression of small mammals. Mammalia 54: $397-404$.

Hansson L. and Henttonen H. 1985. Gradients in density variation of small rodents: The importance of latitude and snow cover. Oecologia (Berl) 67: $394-402$.

Hansson L. and Jaarola M. 1989. Body size related to cyclicity in microtines: Dominance behaviour or digestive efficiency? Oikos 55: $356-364$.

Kaikusalo A. 1972. Population turnover and wintering of the bank vole, Clethrionomys glareolus (Schreb.), in southern and central Finland. Ann. Zool. Fennici 9: 219 - 224.

Krebs C. J. 1978. A review of the Chitty hypothesis of population regulation. Can. J. Zool. 56: $2463-2480$.

Lidicker W. Z., Jr. and Ostfeld R. S. 1991. Extra-large body size in California voles: Causes and fitness consequences. Oikos 61: $108-121$.

Schwarz S. S., Pokrovski A. V., Istchenko V. G., Olenjev N. A., Ovtschinnikova N. A. and Pjastolova O. A'. 1964. Biological pecularities of seasonal generations of rodents, with special reference to the problem of senescence in mammals. Acta theriol. 8: $11-43$.

Taitt M. J. and Krebs C. J. 1985. Population dynamics and cycles. [In: Biology of new world Microtus. R. Tamarin, ed.]. American Sociey of Mammalogists, Pittsburgh: 567 - 620 .

Tanton M. T. 1969. The estimation and biology of populations of the bank vole (Clethrionomys glareolus (Schr.)) and wood mouse (Apodemus sylvaticus (L.)). J. Anim. Ecol. 38: 511 - 530.

Received 11 April 1991, accepted 21 November 1991. 